\title{
DENTAL ERGONOMICS KNOWLEDGE, PRACTICE, AND ATTITUDE ASSESSMENT OF DENTISTS IN UPPER EGYPT: A CROSS-SECTIONAL STUDY
}

\author{
Diaa Salah*, Nagwa Khattab ${ }^{* *}$ and Wael Ahmed ${ }^{* * *}$
}

\begin{abstract}
Ergonomics is the scientific study of people and their working environment. Dentistry is a profession that produces different types of musculoskeletal disorders. If ergonomic principles are applied in dentistry field, it helps to prevent occupational health hazards and provides more comfort to the dentist and patient. The aim of this study was to assess the knowledge, attitude, and practice of group dentists in Upper Egypt regarding to dental ergonomics.

Subjects and methods: a total of 430 dentists were included in the current study after sample size calculation, the equation considering the knowledge of dentists about dental ergonomics, confidence level, and margins of error; then, an additional number of dentists were added to guard against nonresponse. They were randomly selected from four governorates in Upper Egypt (Bani Sweif Minia, Assuit, and Sohag). Data were collected by face-to-face interview using prevalidated questionnaire. The questionnaire consisted of 24 items divided into five sections; first part demonstrates sociodemographic. The second part concerned with the knowledge about dental ergonomics (10 multiple-choice questions). The third part consists of 4 questions to determine attitude of participants, The fourth part consists 5 questions focused on the practice of dentists regarding dental ergonomics and finally, the last part assess musculoskeletal disorders and treatments received of participants (5 questions).Chi-square test was used to compare between the two or more proportions. A correlation was used for describing the relationship or association between two mutually numerical dependent variables and significant level was set at $\mathrm{p}<0.05$.
\end{abstract}

Results: revealed high response rate among participant (93\%). The overall knowledge level in the current study was $11.8 \%$ had good knowledge, more than half had positive attitude towards dental ergonomic and only $8.0 \%$ had good practice.

Conclusion: Dentists in Upper Egypt have problems in their knowledge and practice of dental ergonomics. However, Most of the respondents were interested in improving their knowledge and practice levels through continuing education.

KEYWORDS: Attitude, Dentists, Upper Egypt, Knowledge, Dental ergonomics, Practice

\footnotetext{
* Pediatric and Community Dentistry Department, Faculty of Dentistry, Minia university, Minia. Egypt

** Professor, Pediatric Dentistry and Dental Public Health Department-Faculty of Dentistry-Ain Shams University. Cairo. Egypt

*** Instructor, Pediatric and Community Dentistry Department, Faculty of Dentistry, Minia University, Minia, Egypt
} 


\section{INTRODUCTION}

Dentistry is a visually dependent occupation where the visual demands may require adoption of fixed postures for extended periods of time. Also, the job profile of dentists exposes them during their work to many burdensome and harmful factors which put them at high risk for musculoskeletal disorders ${ }^{1}$.

Musculoskeletal disorders (MSDs) are a wide range of inflammatory and degenerative disorders of muscles, tendons, and nerves which can result in pain and functional impairment affecting the neck, upper back, lower back, shoulders, elbows, wrists, and hands ${ }^{2}$ which can be classified according to their clinical presentation as clinically well-defined (such as tendonitis and carpal tunnel syndrome), less clinically well-defined (such as tension neck syndrome) and nonspecific (such as repetitive strain injury, cumulative trauma disorder, and overuse syndrome) ${ }^{3}$

There are many types of MSDs that related to work and can affect different body parts as; wrist (carpal tunnel syndrome, tendonitis and Guyon's syndrome), fingers (DeQuervain's tenosynovitis and trigger finger), elbow (epicondylitis cubital tunnel syndrome), shoulders (bursitis, thoracic outlet syndrome, rotator cuff tear and rotator cuff tendonitis), neck (myofascial pain disorder and cervical spondylosis), and back (general pain, disc problems and sciatica ${ }^{4}$. These disorders can result in detrimental effects on work efficiency among dental surgeons ${ }^{5}$.

The prevalence and severity of these disorders decrease by adopting ergonomic interventions ${ }^{6}$ which was defined by International Ergonomic Association (IEA) as the scientific discipline concerned with the understanding of the interactions among humans and other elements of a system, and the profession that applies theoretical principles, data and methods to design in order to optimize human well-being and overall system ${ }^{7}$.

The IAE categorizes ergonomics into three specific domains of physical ergonomics, cognitive ergonomics, and organizational ergonomics ${ }^{8}$. Physical ergonomics was consisted of interventions aimed at following factors; (1) operator factors (e.g. adopting right work posture, appropriate use of patient and dentist chair, or correct method of instrumentation and tool handling), (2) office design factors (e.g. workstation layout, or set-up of space for positioning of operators, patients, machines, delivery systems, and their interrelationships), and (3) dental equipment design factors (e.g. ergonomically designed operator and patient chairs, instruments, and visual aids). ${ }^{9}$

While, cognitive ergonomics aimed to decrease psychosocial stress, caused by job demands, such as the number of patients seen, or hours worked, and job control, is associated with MSDs in dental practitioners..$^{\mathbf{1 0}}$, organizational ergonomics was concerned with different organization of the work, such as organization of workflow, appointment scheduling by alternating easy and difficult cases, working with dental assistants, buffer periods and breaks for rest and stretching ${ }^{11}$.

Many authors reported the prevalence of MSDs in between dentists was to be high ${ }^{12,13,14}$. In Egypt, literature review of Egyptian dentists' knowledge and practice demonstrated fair to poor knowledge and poor practice in studies of El-sallamy et al.,2018 and Alaa and Younis., 2020 ${ }^{15,16}$ in Tanta and Cairo governments respectively which represented Lower Egypt dental society. While there were no previous studies published to assess knowledge, practice or attitude about ergonomics in Upper Egypt dental society. Therefore the current study was carried out to through light about dental ergonomics among dentists in Upper Egypt.

\section{PARTICIPANTS AND METHODS}

The study was approved from the Ethics Committee of Faculty of Dentistry, Minia University. The present cross-sectional study was employed a survey to assess knowledge, practice or attitude about ergonomics in Upper Egypt dental dentists 
in 4 governments (Bani Sweif, Minia, Assuit, and Sohag ). The study was conducted during the period from January 2018 to August 2019.

The sample size estimation was done using Steven., $1987^{17}$ equation and assuming power 95 $\%$ and alpha error 0.05 which resulted in a size of 384.158 dentists then $10 \%$ of the calculated sample size was assumed for incomplete surveys and nonrespondent percentage of the participants. Total of 430 participants were included in this study.

Surveying literature was carried out to find suitable instrument for assessment of "knowledge, attitude and practice of dentists regarding dental ergonomic, the results rendered several published studies using questionnaire. A validated questionnaire which assessed the prevalence of MSDs and knowledge, attitude or practice about ergonomics in between dentists ${ }^{18,19}$ was used. The questionnaire was pretested by conducting pilot study with 20 dentists. After analyzing the pretest data, Cronbachs alpha correlation coefficient $\alpha=0.91$ indicating the survey had high degree of internal consistency. The results of pilot study were not included into the results of the current study.

The face-to-face interview method was to complete the study questionnaire from voluntary participated dentists working in hospitals of Egyptian Ministry of Health, private clinics or both in selected governments. The participants were of all academic degrees (bachelor, master and doctoral degree) except for pediatric dentistry specialists.

The questionnaire consisted of the following sections: 1) a cover information sheet that contained participant contact information, participation invitation and study summary, 2) demographic data section, 3) knowledge assessment section (10 questions), 4) attitude assessment section (4 questions), 5) practice assessment section (5 questions) and 6) MSDs assessment (5 questions).

For scoring of provided categorical data of knowledge, the answers was (yes, to some extent, and no) and scored as 2, 1, and 0 . The total score of knowledge was summed. It ranged from 0 to 20 . Those who achieved $\geq 75 \%$ from the total score $(\geq 15)$ was considered as good knowledge, those from $50-<75 \%(10-14)$ was fair knowledge, and below 50\% (below 10) was considered as poor knowledge. ${ }^{15}$

For attitude and practice scoring, the answers were assessed on a 5-point Likert scale; they were definitely yes, yes, neutral, no, and definitely no for attitude and always, very often, often, rare, and never for practice with score ranged from 0 to 4 . The total score ranged from 0 to 16 was set for attitude and from 0 to 20 for practice. Those who achieved $\geq 75 \%$ from the total score ( $\geq 12$ for attitude and $\geq 15$ for practice) was considered to have a positive attitude and good practice respectively, while less than $75 \%$ ( $<12$ for attitude and $<15$ for practice) considered to have a negative attitude and poor practice respectively. ${ }^{18}$

Statistical analysis was performed with IBM SPSS Statistics 20.0 (SPSS Inc., Chicago, IL, USA) using Chi-square test for categorical variables, to compare between different groups, Fisher's Exact for correction of chi-square when more than $20 \%$ of the cells have expected count less than 5, Monte Carlo correction or Pearson coefficient to correlate between two normally distributed quantitative variables The significance level was set at $\mathrm{p}<0.05$.

\section{RESULTS}

Out of 430 questionnaires, 400 fulfilled questionnaires were adopted for statistical analysis whereas 30 incomplete questionnaires have been excluded. The response rate in this study was high, $400(93 \%)$. Statistical analysis of demographic data revealed that $55 \%$ of the participants were males (220) and $45 \%$ were females (180) with $\mathrm{P}$ value was 0.045 . (71) $17.8 \%$ employed in public hospital, (63) $15.8 \%$ in private clinics and (266) $66.5 \%$ work in both with $\mathrm{P}$ value was $<0.001$. The results also, showed that $34 \%, 54.3 \%, 7 \%, 4.8 \%$ and $1.3 \%$ of the participant were in the ages groups 25-30, 31-35, 
36-40, 41-45 and 46-50 years old respectively. The mean of age was $31.92 \pm 3.98$ and the $\mathrm{P}$ value was $<0.001$.

The majority of the participants are GP (82.8\%), while those with postgraduate degree (Diploma / Master) were $17.2 \%$ degree and the $\mathrm{P}$ value was< 0.001. As regards years of dental practice, the majority of the participants (257) had 6-10 years of clinical practice $(64.3 \%)$, followed by $24.0 \%$ (96), $5.8 \%$ (23) and 5\% (20) had years of dental practice $1-5$ years, $11-15,16-20$ respectively, the mean was $7.86 \pm 3.87$ 71years and the $\mathrm{P}$ value was $<0.001$.

Regarding to knowledge results of the current study demonstrated that there were 143(35.8\%) know what is meant by ergonomics, $147(36.8 \%)$ know what are the health hazards of their job without ergonomics. Also, it was found that 148 (37\%) know the benefits of ergonomic application, 164(41\%) know the popular operating posture that may cause musculoskeletal disorders, 176(44\%) know the best posture of the dentist sitting,149(37.3\%) know the best level of the dentist shoulders and site of elbow and upper arms. 107(26.8\%) know the degree of the sight-line and the light-line for prevent neck bending and shadow of light in operation field,(32.3\%) know the ideal design of dental stool and dental chair, $112(28 \%)$ know the ergonomic head rest and its benefits, 107(26.8\%) know the moving exercise, and stretch exercise between patient's appointments.

While attitude assessment results revealed that $74 \%$ of participants thought that ergonomics should be a part of the dental curriculum, 73.3\% of dentists know that they should follow the ergonomic principles in routine dental practice, $78 \%$ of participants thought that dental chair and instruments play role in following ergonomic principles in routine dental practice. Also $73.5 \%$ of the dentist assumed that they should conduct continuing education in updates of ergonomic.

However, only $12.5 \%$ and $25.8 \%$ of dentist use dental loupes for magnification purposes and work in the upright position and their spine resting on the back of the stool respectively. About 36.5\% of dentist work with their legs separated and their feet flat on the floor. Moreover 69.3\% and 66.5\% do not orient the operating field to the elbow level or beam of light perpendicular to the observational direction.

Assessment of MSDs, revealed that 161(40.3\%) of the participant had complain related to Wrist / Hand, 215(53.8\%) had complain related to Neck/ shoulder and $219(54.8 \%$ ) had complain related to Low/ high back. Also, 210(52.5\%) had complain related to knees, ankles and feet's and 51(12.8\%) had received a treatment for some form of musculoskeletal disorders.

Over all Evaluation of dentist' knowledge, attitude and practice reveled that only (11.8\%) of them had high knowledge and about (8\%) of them had good practice. However more than half of dentist $(58.5 \%)$ had a favorable attitude toward dental ergonomic (Table1)

TABLE (1): Rating of dentists' knowledge, practice and attitude.

\begin{tabular}{|c|c|c|c|c|}
\hline & Level & Frequency & Percentage & P value \\
\hline Knowledge(10 questions) & Poor $<50 \%$ & 215 & $53.8 \%$ & $0.001^{*}$ \\
& Fair 50- $<75 \%$ & 138 & $34.5 \%$ & \\
& Good $\geq 75 \%$ & 47 & $11.8 \%$ & $0.0006^{*}$ \\
\hline Attitude (5 questions) & Negative $<75 \%$ & 166 & $41.5 \%$ & $58.5 \%$ \\
& Positive $\geq 75 \%$ & 234 & $92.0 \%$ & $0.001^{*}$ \\
\hline Practice (5 questions) & Bad ergonomic $<75 \%$ & 368 & $8.0 \%$ & \\
& Good practice $\geq 75 \%$ & 32 & & \\
\hline
\end{tabular}


There was a positive correlation between overall knowledge and overall relevant practice with significance $(\mathrm{R}=0.349$ and $\mathrm{P}<0.001)$. For assessment of relations between different study variables with demographic data There were a highly significant difference between overall knowledge, attitude and practice with age, last scientific degree and years of practical experience, while there was no significant difference between previously mentioned variables with gender or workplace (Table 2).There was a highly statistical significant difference $(\mathrm{P}<0.001)$ between overall knowledge and overall relevant practice with demographic data as regard to age (knowledge and practice decrease as age increased), last scientific degree (knowledge and practice increased as scientific degree increased) and years of practical experience (knowledge and practice decreased as practical experience increased). Also there was a highly statistical significant difference $(\mathrm{P}<0.001)$ between overall attitude with demographic data as regard to age (attitude increased as age increased), last scientific degree (attitude increased as scientific degree increased) and years of practical experience (attitude increased as practical experience increased).

TABLE (2): Relations between different study variables with demographic characteristics

\begin{tabular}{|c|c|c|c|c|c|c|c|c|}
\hline \multirow[t]{2}{*}{ Demographic Data } & \multicolumn{3}{|c|}{ Over all Knowledge } & \multicolumn{2}{|c|}{ Overall Attitude } & \multicolumn{2}{|c|}{ Overall practice } & \multirow[t]{2}{*}{$\mathbf{P}$} \\
\hline & $\begin{array}{c}\text { Poor } \\
(<50 \%) \\
(n=215)\end{array}$ & $\begin{array}{l}\text { Fair }(50- \\
<75 \%) \\
(n=138)\end{array}$ & $\begin{array}{c}\text { Good } \\
(\geq 75 \%) \\
(n=47)\end{array}$ & $\begin{array}{l}\text { Negative } \\
(<75 \%) \\
(n=166)\end{array}$ & $\begin{array}{l}\text { Positive } \\
(\leq 75 \%) \\
(n=234)\end{array}$ & $\begin{array}{c}\text { Bad } \\
(<75 \%) \\
(n=368)\end{array}$ & $\begin{array}{c}\text { Good } \\
(\geq 75 \%) \\
(n=32)\end{array}$ & \\
\hline Age(years) & & & & & & & & $<0.001$ \\
\hline $25-30(n=136)$ & $43(31.6 \%)$ & $59(43.4 \%)$ & $34(25 \%)$ & $91(66.1 \%)$ & $45(33.1 \%)$ & $116(85.3 \%)$ & $20(14.7 \%)$ & \\
\hline $31-35(n=217)$ & $139(64.1 \%)$ & $65(29.9 \%)$ & $13(6 \%)$ & $74(34.1 \%)$ & $143(65.9 \%)$ & $206(94.9 \%)$ & $11(5.1 \%)$ & \\
\hline $36-40(n=28)$ & $19(67.8 \%)$ & $9(32.2 \%)$ & $0(0 \%)$ & $1(3.5 \%)$ & $27(96.5 \%)$ & $27(96.5 \%)$ & $1(3.5 \%)$ & \\
\hline $41-45(n=14)$ & $10(71.4 \%)$ & $4(28.6 \%)$ & $0(0 \%)$ & $0(0 \%)$ & $14(100 \%)$ & $14(100 \%)$ & $0(0 \%)$ & \\
\hline $46-50(n=5)$ & $4(80 \%)$ & $1(20 \%)$ & $0(0 \%)$ & $0(0 \%)$ & $5(100 \%)$ & $5(100 \%)$ & $0(0 \%)$ & \\
\hline Gender & & & & & & & & $>0.05$ \\
\hline Male $(n=220)$ & $112(50.9 \%)$ & $79(35.9 \%)$ & $29(13.2 \%)$ & $89(40.5 \%)$ & $131(59.5 \%)$ & 201(91.4\%) & $19(8.6 \%)$ & \\
\hline Female $(\mathrm{n}=180)$ & $103(57.2 \%)$ & $59(32.7 \%)$ & $18(10.1 \%)$ & $77(42.7 \%)$ & $103(57.3 \%)$ & $167(92.7 \%)$ & $13(7.3 \%)$ & \\
\hline scientific degree & & & & & & & & $<0.001$ \\
\hline $\mathrm{GP}(\mathrm{n}=331)$ & $215(64.9 \%)$ & $103(31 \%)$ & $13(4.1 \%)$ & $145(43.8 \%)$ & $186(56.2 \%)$ & $316(95.4 \%)$ & $15(4.6 \%)$ & \\
\hline Specialist(n=69) & $0(0 \%)$ & $35(50.7 \%)$ & $34(49.3 \%)$ & $21(30.5 \%)$ & $48(69.5 \%)$ & $52(75.3 \%)$ & $17(24.7 \%)$ & \\
\hline $\begin{array}{c}\text { Years of practical } \\
\text { experience }\end{array}$ & & & & & & & & $<0.001$ \\
\hline $1-5(n=96)$ & $28(29.1 \%)$ & $39(40.6 \%)$ & $29(30.3 \%)$ & $77(80.3 \%)$ & $19(19.7 \%)$ & $78(81.2 \%)$ & $18(18.8 \%)$ & \\
\hline $6-10(n=257)$ & $153(59.5 \%)$ & $86(33.4 \%)$ & $18(7.1 \%)$ & $88(34.3 \%)$ & $169(65.7 \%)$ & $244(94.9 \%)$ & $13(5.1 \%)$ & \\
\hline $11-15(n=23)$ & $15(65.2 \%)$ & $8(34.8 \%)$ & $0(0 \%)$ & $1(4.4 \%)$ & $22(95.6 \%)$ & $22(95.6 \%)$ & $1(4.4 \%)$ & \\
\hline $16-20(n=20)$ & $15(75 \%)$ & $5(25 \%)$ & $0(0 \%)$ & $0(0 \%)$ & $20(100 \%)$ & $20(100 \%)$ & $0(0 \%)$ & \\
\hline $21-25(n=4)$ & $4(100 \%)$ & $0(0 \%)$ & $0(0 \%)$ & $0(0 \%)$ & $4(100 \%)$ & $4(100 \%)$ & $0(0 \%)$ & \\
\hline Workplace & & & & & & & & $>0.05$ \\
\hline Hospital(n=71) & $41(57.7 \%)$ & $22(30.9 \%)$ & $8(11.4 \%)$ & $35(49.3 \%)$ & $36(50.7 \%)$ & $64(90.1 \%)$ & $7(9.9 \%)$ & \\
\hline Clinic $(n=63)$ & $31(49.2 \%)$ & $26(41.2 \%)$ & $6(9.6 \%)$ & $20(31.8 \%)$ & $43(68.2 \%)$ & $58(92 \%)$ & $5(8 \%)$ & \\
\hline Both $(n=266)$ & $143(53.7 \%)$ & $90(33.8 \%)$ & $33(12.5 \%)$ & $111(41.7 \%)$ & $155(58.3 \%)$ & $246(92.4 \%)$ & $20(7.6 \%)$ & \\
\hline
\end{tabular}




\section{DISCUSSION}

Dental ergonomics were recognized as ideal techniques to prevent work related musculoskeletal disorders that were reported to affect large population of dentists causing determinal effects in their health, work efficiency and financials ${ }^{20}$ Therefore, the current study was conducted to assess knowledge, attitude and practice of dentists of Upper Egypt society about dental ergonomics with efficient sample size and study design providing a solid data for comparison with other populations.

Sample was obtained from four governments (Bani Sweif, Minia, Assuit, and Sohag)) as these governments represented the main bulk of dentists distribution in Upper Egypt society as recorded by Egyptian dental syndicate up to January 2018 . Pediatric dentistry specialists were excluded from sample participants as their qualifications made them more familiar with dental ergonomics practice thus might affect result generalization through providing over-estimated results (interpretation bias)

In the current study a face to face interview was used to complete predesigned validated selfadministered questionnaire, which was also, pilot tested before implementation of the study, therefore providing high quality accurate data than other methods. Moreover, the availability to explain questionnaire to participants which was reflected in a high response rate of (93\%) being comparable with that reported by Feng et al., $2014^{12}(89.5 \%)$, however, it was clearly higher than that reported by Kritika et al., 2014 ${ }^{18}$ (67\%) who used electronic method to deliver the questionnaire.

The current study results demonstrated that the majority of participants had poor knowledge about ergonomics $(53.8 \%)$ followed by fair knowledge of (34.4\%) and good knowledge of (11.8\%). Thus coincided with results reported by Garbin et al., $2011{ }^{21}$ in Brazil and Siddiqui et al., 2016 ${ }^{22}$ in Pakistain, in which knowledge was showed to be $65 \%$ poor, $19.5 \%$ fair and $14.4 \% \operatorname{good}$ for first study and $40.1 \%$ poor, $38.4 \%$ fair and $21.4 \%$ good for second study. However, higher level of knowledge was reported by Munaga et al., 2013 ${ }^{23}$ and Kalghatgi et al.,2014 $^{19}$ among Indian dentists

As regard to attitude of dentists to dental ergonomic, the results revealed $58.5 \%$ positive and $41.5 \%$ of negative attitude for participants being higher than that reported by Garbin et al., 2011 ${ }^{21}$ and Siddiqui et al., 2016 ${ }^{22}$ who reported unsatisfactory attitude among Brazilian and Pakistanis dentists respectively. On the other hand, it was lower than that reported by Kalghatgi et al., 2014 ${ }^{19}$ how reported $75 \%$ of participants had a positive attitude this differences could be attributed to difference in study population; the author population included dental professionals of a dental institute. Also it was lower than that reported by $\boldsymbol{E}$ l-sallamy et al., $2018^{15}$ how reported $84.8 \%$ of participants to have positive attitude this difference could be attributed to difference in study population; the author population included dental students in Tanta University.

Also, the current study recorded that $92 \%$ of participants demonstrated a poor practice of dental ergonomics, this goes in accordance with previous results recorded by Munaga et al., $2013^{23}$, Siddiqui et al., 2016 ${ }^{22}$ and El-sallamy et al., $2018^{15}$.

There was a positive strong correlation between overall knowledge and overall relevant practice with high significance that coincide with results reported by El-sallamy et al., 2018 ${ }^{15}$ who demonstrated a statistical significant relation between knowledge and practice. While a study performed by Kalghatgi et al., $2014{ }^{19}$ demonstrated an insignificant relation thus might be due to deficient training and theoretical understanding of ergonomic principles.

For assessment of relations between different study variables with demographic data, there was a highly statistical significant difference $(\mathrm{P}<0.001)$ between overall knowledge and overall relevant practice with last scientific degree where good knowledge and proper practice increased with higher 
scientific .Also, it was observed that knowledge and practice about dental ergonomics decreased as age and years of practical experience increase. This might be due to absence of dental ergonomics education curriculum of dental schools in Egyptian universities for older graduated dentists.

Also there was a highly statistical significant difference $(\mathrm{P}<0.001)$ between overall attitude with demographic data as regard to age, last scientific degree and years of practical experience, with increasing in age and years of clinical experience would results in more pronounced work related musculoskeletal problems ${ }^{24}$

These results coordinated with Kritika et al., $2014^{18}$ and Kalghatgi et al. $2014^{19}$ who reported significant association between knowledge, attitude and practice with academic level of education and no significant association with other demographic characteristics. The difference may be attributed to differences in target population studied, however it rises the need for continuous education, motivation and training about ergonomics.

The current study limitations included the following; sample obtained from only four governments of Upper Egypt which not reflecting all Upper Egypt population,, the limited number of specialists included, and the designed questionnaire did not assess involvement of dental ergonomic within the curriculum of dental students.

\section{CONCLUSIONS}

1. Dentists in Upper Egypt have obvious problems in their knowledge of dental ergonomics. Unfortunately, these shortages in knowledge and practice are a real cause of musculoskeletal disorder.

2. Most of the respondents were interested in improving their knowledge and practice levels through continuing education.

\section{RECOMMENDATIONS}

1. It is highly recommended to apply continues education and training programs in the form of lectures, courses, or workshops through cooperation between universities especially, in Upper Egypt and Egyptian Ministry of Health.

2. Revising and updating the current dental ergonomics educational curricula in dental schools.

\section{ACKNOWLEDGEMENTS}

The authors are greatly indebted to all dentists for their participation in this survey.

\section{REFERENCES}

1. Khare A and Gupta A. Imbursement Array in Dental Practice Management A Review. Journal of Orofacial Research. 2018; 7(3): 32-35.

2. Center of Disease Control. NIOSH Program Portfoli. Musculoskeletal Disorders- : Program Description".www.cdc.gov. Retrieved- 2016-03-24.

3. Hales TR. Ergonomics and upper extremity musculoskeletal disorders. Physical and Biological Hazards of the Workplace. 2016; 30:13-32.

4. Pejčić N, Petrović V, Marković D, Miličić B, Dimitrijević II, Perunović N, Čakić S. Assessment of risk factors and preventive measures and their relations to work-related musculoskeletal pain among dentists. Work. 2017; 57(4): 573-93.

5. Alyahya F, Algarzaie K, Alsubeh Y, Khounganian R. Awareness of ergonomics \& work-related musculoskeletal disorders among dental professionals and students in Riyadh, Saudi Arabia. Journal of physical therapy science. 2018; 30(6):770-776.

6. 6-Elbert KK, Kroemer HB, Hoffman AD. Ergonomics: how to design for ease and efficiency. Academic Press; 2018: p.366-377.

7. International Ergonomics Association.- What is ergonomics - definition and domains of ergonomics.www.iea.cc/whats/index.html- (accessed 10 July 2020).

8. Mulimani P, Hoe VC, Hayes MJ, Idiculla JJ, Abas AB, Karanth L. Ergonomic interventions for preventing mus- 
culoskeletal disorders in dental care practitioners. Cochrane Database of Systematic Reviews. 2018; 10: 1-40.

9. Grubišić F. Are ergonomic interventions effective for preventing musculoskeletal disorders in dental care practitioners?-A Cochrane Review summary with commentary. Musculoskeletal science \& practice. 2019; 44: 1-30.

10. De Sio S, Traversini V, Rinaldo F, Colasanti V, Buomprisco G, Perri R, Mormone F, La Torre G, Guerra F. Ergonomic risk and preventive measures of musculoskeletal disorders in the dentistry environment: an umbrella review. PeerJ Journal. 2018; 6: 1-16.

11. Kuiper A, de Mast J, Mandjes M. The problem of appointment scheduling in outpatient clinics: A multiple case study of clinical practice. Omega. 2019; 18: 102-122.

12. Feng B, Liang Q, Wang Y, Andersen LL, Szeto G. Prevalence of work-related musculoskeletal symptoms of the neck and upper extremity among dentists in China. Peer-reviewed journal. 2014; 12: 1-8.

13. Hassan EE, El-khateeb AS, Ewis AA, Ali AN. Musculoskeletal disorder among dentists and physicians at minia university hospitals. Egyptian Journal of Occupational Medicine. 2017; 41(1): 55-70.

14. Ohlendorf D, Naser A, Haas Y, Haenel J, Fraeulin L, Holzgreve F, Erbe C, Betz W, Wanke EM, Brueggmann D, Nienhaus A. Prevalence of Musculoskeletal Disorders among Dentists and Dental Students in Germany. International Journal of Environmental Research and Public Health. 2020; 17(23): 1-19.

15. El-sallamy RM, Atlam SA, Kabbash I, Abd El-fatah S, El-flaky A.Knowledge, attitude, and practice towards ergonomics among undergraduates of Faculty of Dentistry, Tanta University, Egypt. Environmental Science and Pollution Research. 2018; 25(31): 30793-30801.

16. Alaa E and Younis SH .Assessment of Ergonomics Interventional Educational Program on Knowledge,
Attitude, Practice and Behavior among a Group of Egyptian Dental Students. Egyptian Dental Journal. 2020; 66(1):623-632.

17. Steven K. Thompson- Sample Size for Estimating Multinomial Proportions,- The American Statistician,1987;41(1):- 42-46.

18. Kritika V, Laveena P, Kritika R, Jatin A, Aashish P, Jagjeet S. Knowledge, attitude and behavior towards "ERGONOMICS" among oral health professionals in jodhpur city, Rajasthan, India. International Journal of Preventive and Clinical Dental Research. 2014; 1(3): 5-9.

19. Kalghatgi S, Prasad KV, Chhabra KG, Deolia S, Chhabra C. Insights into ergonomics among dental professionals of a dental institute and private practitioners in hublidharwad twin cities, India. Safety and health at work. 2014; 5(4): 181-185.

20. Sachdeva A, Bhateja S, Arora G. Ergonomics in dentistry: A comprehensive review. Journal of Dental Research and Review. 2020; 7(1):32-35.

21. Garbin AÍ, Garbin CA, Diniz DG, Yarid SD. Dental students' knowledge of ergonomic postural requirements and their application during clinical care. European Journal of Dental Education. 2011; 15(1): 31-35.

22. Siddiqui TM, Wali A, Khan $\mathrm{OH}$, Khan M, Zafar F. Assessment of knowledge, practice, and work environment related to ergonomics among dental students and dental practitioners. International Journal of Contemporary Dental \& Medical Reviews. 2016; 2016: 1-5.

23. Munaga S, Rawtiya M, Khan S, Chitumalla R, Kubagiri SK, Sajjan P. Assessment of knowledge, practices, and work place condition related to ergonomics among dental students of Bhopal city-A questionnaire study. Journal of Orofacial Sciences. 2013; 5(2): 109-113.

24. Biradar SV andNarayan DP. Occupational Hazards in Dentistry-A Review. Asian Journal of Pharmaceutical Technology and Innovation. 2018; 6: 67-75. 